\section{B A Institute of \\ YK Business Administration \\ TK Karachi \\ Leadership and Ideas for Tomorrow}

Article 9

Volume 4 Issue 1 January-June 2009

$1-1-2009$

\title{
Panel data models: An appraisal of lead-lag relation in the KSE-30
}

Muhammad Ayub Siddiqui

International Islamic University, Islamabad, Pakistan

Follow this and additional works at: https://ir.iba.edu.pk/businessreview

Part of the Business Analytics Commons, and the Finance and Financial Management Commons

(c) (i)

This work is licensed under a Creative Commons Attribution 4.0 International License.

\section{Recommended Citation}

Siddiqui, M. A. (2009). Panel data models: An appraisal of lead-lag relation in the KSE-30. Business

Review, 4(1), 159-176. Retrieved from https://doi.org/10.54784/1990-6587.1171

This article is brought to you by iRepository for open access under the Creative Commons Attribution 4.0 License and is available at https://ir.iba.edu.pk/businessreview/vol4/iss1/9. For more information, please contact irepository@iba.edu.pk. 


\title{
DISCUSSION
}

\section{Panel Data Models: An Appraisal Of Lead- Lag Relation In The Kse-30}

\author{
Muhammad Ayub Siddiqui \\ International Islamic University \\ Islamabad, Pakistan
}

\begin{abstract}
S
The lead-lag relation between index futures and the underlying index has been at the core of discussion of the researchers in the developing and the developed world. This study examines the lead-lag relationship between spot and future prices of 21 companies from the KSE-30 Index for the monthly data of the period from October 2004 to February 2008. It applies panel data estimation techniques of common constants, fixed effects and random effects. These estimations are considered to be the most recent and efficient analytical methods in handling econometric data. The data is balanced; therefore, no additional assumption has been employed. The common constants were estimated under the principle assumption of no differences among the data matrices of cross-sectional dimension. For the validity of the fixed effects, F-statistic with the assumption of homogeneity of constants against the heterogeneity proved significance of the fixed effect; notwithstanding our data of stock prices is very reasonably volatile. Yet, in order to get more satisfactory results, this study also estimates random effects. Both the GLS transformed regressions and unweighted statistics in terms of random effects are relatively better for the causal effect of future on the spot. In order to make a choice between the fixed effects and random effects, the Hausman Test was applied; which proved that the fixed effects will be always more consistent for these types of volatile data than random effects.
\end{abstract}

Keywords: lead-lag relation, index futures, spot market, panel models.

JEL Classifications: G14/G15

\section{INTRODUCTION}

Investigating the lead-lag relation between the future and spot prices is the focus of this paper. The lead-lag relation between the futures and spot markets can be affected by the constraints, such as the lack of institutional and regulatory framework of short selling of stocks. According to Modest and Sundaresan (1983), in a frictionless market, the contemporaneous returns of an index futures contract and its underlying index should be perfectly and positively correlated to avoid arbitrage. A lead-lag phenomenon reflects the situation when the two prices move in a sequence. A number of studies ${ }^{\mathrm{i}}$ have estimated even the timings of relation of lead and lag between the futures and the spot. Most of the studies apply error-correction methods, 
Granger Causality and VAR tests to examine the lead-lag relationship ${ }^{\text {ii }}$. This study examines the two way causation between the returns on the spot and future prices using the monthly data by employing panel data techniques such as common constants, fixed effects and random effects.

Panel data estimations are considered to be the most recent and efficient analytical methods in handling econometric data. In the lead-lag relationship, this paper, perhaps, is the first attempt to determine the causal relationship between the returns from the future and the spot prices of the stocks. The same data was employed in the methodologies such as VAR impulse response functions, unit roots and Granger Causality tests in order to measure the lead-lag relationship but no clear relationship could be ascertained.

The popularity of panel data analysis among economists and researchers can be due to the important feature that it allows the inclusion of data for a number of crosssections. Additionally, panel data methodology provides more efficient estimation of parameters by considering broader sources of variation, and the results from this methodology outsource more information to the analyst. They also allow the study of the dynamic behaviour of the parameters ${ }^{\mathrm{iii}}$.

A common problem of time-series estimations is that while estimating samples with very few observations, it is difficult for the analyst to obtain significant t- ratios or $\mathrm{F}$ -statistics from regressions. This problem is more common with annual data estimations in the developing economies, including Pakistan, where very few annual series extend more than 50-60 years. Panel studies are considered to be the most extensive way of testing statistical samples, as they supplement all previous studies and successfully answer causality issues.

Sections 2, 3, 4, after the introduction, present review of literature, methodology, results and analysis respectively. Section 5 concludes the paper with some recommendations of policies and further research.

\section{REVIEW OF LITERATURE}

The literature related to the area of lead-lag relation can be divided into three categories:

1) The lead-lag relation between futures and cash markets

2) The short-selling restrictions

3) The factors affecting the lead-lag relation 
This study addresses the very first area of lead-lag relation on account of the data constraints. Methodologies employed by the previous studies can be outlined as follows:

1) ARMA-Auto regressive moving average

2) VAR-Vector auto regression

3) ECM-Error correction methods

4) Granger Causality

5) ADF-unit roots tests (Augmented dickey fuller)

Whereas this study employs panel data models for the reasons specified in the introduction.

The forward and future stock price index in most of the studies ${ }^{\text {iv }}$ is considered to determine the underlying index. With arbitrage being a costly and risky activity, lead-lag relation between the two prices would be a natural phenomenon. This phenomenon results in mispricing in the market and reverts to a negative mean value $^{\mathrm{v}}$. The cost of arbitrage includes the transaction cost of trading the futures, the financing cost for the margin deposits for each side of the position and so on. Additionally, the risk of arbitrage consists of execution, uncertainty in respect of interest rates, and dividend payments ${ }^{\mathrm{vi}}$. The lead-lag relation between the futures and spot markets can be affected by the constraints such as the lack of institutional and regulatory framework of short selling of stocks. This lead-lag relation is the focus of this paper.

Given the weaknesses of manual trading and order-routing system, a gap between cash and derivatives markets has been observed during extreme market conditions ${ }^{\mathrm{vii}}$. In the KSE, the stocks are traded on-screen through the Automatic Matching System (AMS). AMS enables traders to obtain immediate order execution via computers, through brokers, linked to the central computer of the exchange. The futures are traded in with the conventional open outcry method in the KSE. In some markets, brokers cans levy a fee against short-sellers for borrowing stocks. The restrictions on short selling generally impose extra cost on arbitragers whenever short selling of stocks is needed. Some studies ${ }^{\text {viii }}$ show that restrictions against short selling slow the downward adjustment to negative information of stock prices. This obviously suggests that the futures should lead the cash index by a greater extent in a falling. This relation may be attributed to the fact that futures are settled daily, and no stochastic interest rates and dividend flows can drive a gap between the prices of the forward and futures but this gap between the two prices is negligible ${ }^{\text {ix }}$. The shortselling restrictions explain a portion of the variation in the lead-lag relation ${ }^{\mathrm{x}}$. Therefore, removal of restrictions should effectively reduce the extent of the lead-lag relation between the index futures and the cash index. Moreover, relaxing the constraints against short-selling should increase the contemporaneous correlation between changes in the two prices. 
Chan (1992) finds that the lead-lag relation is not affected by whether the market is rising or falling. Chan also postulates that futures should lead when information is market-wide and spot indexes would lead when information is firm-specific. This study examines the lead-lag contemporaneous relation for the 21 stocks selected from the KSE-30 companies over the periods from October 2004 to February 2008.

\section{METHODOLOGY ${ }^{\mathrm{xi}}$}

In general, simple linear panel data models are estimated, depending upon the type of data, by the following three different methods:
(a) Common constants;
(b) Allowing for fixed effects, and
(c) Allowing for random effects.

\subsection{THE COMMON CONSTANT METHOD}

The hypothesis for common constant assumes that the data set is a priori homogeneous.

The common constant method, presents results under the principal assumption that there are no differences among the data matrices of the cross-sectional dimension. This, in other words, means estimation of common constant for all cross-sections. For example, there is common constant for all the 21 companies in the study under consideration. Practically, the common constant method implies that there are no differences between the estimated cross-sections.

\subsection{THE FIXED EFFECTS METHOD}

In the fixed effects method, the constant is treated as group or company-specific and there is a different constant for each stock or company. The fixed effects estimator is also known as the least-squares dummy variables (LSDV) estimator. The dummy variable is the one that allows us to take different group-specific estimates for each of the constants for every different company/stock.

The fixed effects model has the following problems:

1. It ignores all explanatory variables that do not vary over time. This way it compels us avoid using other dummies in the model, such as days of the week in case of daily data, months of the year and other dummy variables.

2. It is very inefficient because it estimates a very large number of parameters. Hence, it uses up greater degree of freedom. 
3. It makes it very hard for any slowly changing explanatory variables to be included in the model, because they will be highly collinear with the effects.

Nevertheless, our data set of stock prices frequently changes over time. Yet this study also employs the random effects method in order to understand the data more resiliently. It also employs Hausman test to make a choice between the random effects and the fixed effects.

\subsection{THE RANDOM EFFECTS METHOD}

This is an alternative method of estimating a model. The difference between the fixed effects and the random effects method is that the latter handles constants for each section not as fixed, but as random parameters the variability of which, for each stock, comes from the fact of including random error term.

In this approach, we need to make specific assumptions about the distribution of the random component. The random effects model has the following advantages:

1. It has fewer parameters to estimate as compared to the fixed effects method.

2 It allows for additional explanatory variables that have equal value for all observations within a group including the use of dummies.

The use of random effects estimator is superior to the fixed effects estimator, because the former is the GLS estimator and the latter is actually a limited case of the random effects model, as it corresponds to the cases where variation in individual effects is relatively large. The fixed effects model assumes that each stock/company differs in its intercept term, whereas the random effects model assumes that each stock/company differs in its error term.

Usually, when the panel is balanced as is the case of present study, one might expect the fixed effects model working the best. However, in the cases where the sample contains limited observations of the existing cross-sectional units, the random effects model might be more appropriate.

The Hausman test is the criterion in making a choice between the fixed effects and random effects models. Hausman (1978) adapted a test based on the idea that under the hypothesis of no correlation, both OLS and GLS are consistent but OLS is inefficient; while under the alternative, OLS is consistent and GLS is not. Given a panel data model, the Hausman test investigates whether random effects estimation could be almost as good as fixed effects estimation. In a way, the Hausman statistic 
is a distance measure between the fixed effects and the random effects estimators ${ }^{\mathrm{xi}}$. If the value of the statistic is large, then the difference between the estimates is significant, as is the result of this study; so, we reject the null hypothesis that the random effects model is consistent and we use the fixed effects estimators. The Hausman test for this study strongly recommends the fixed effects model. In contrast, a small value of the Hausman statistic implies that the random effects estimator is more appropriate.

\section{RESULTS AND ANALYSIS}

Our model is balanced panel in the sense that no value is missing either across the periods, which ranges from 2004:10 to 2008:02 for all the companies, or across the groups of stocks. So, there is no question of heterogeneity in this panel and consequently there is no need for any additional assumptions.

\subsection{COMMON CONSTANTS}

For the common constant we have tested the model using pooled OLS under the principle assumption of no differences among the data matrices of cross-sectional dimension. With this context, two way pooled regression results have been obtained and reported in the Tables 1-a and 1-b for perusal. SR and FR represent returns series from spot prices and future prices respectively.

Though the results are statistically significant for both the cases, SR as repressor (Table 1-b) as well as FR as repressor (Table 1-a); and the diagnostic tests, such as Sum of the Squared residuals, and Adjusted R-squared prove to be identical for both. Standard error of the regression recommends the second model. The graphs of the residuals for all the 21 stocks have also been shown above. For almost all the stocks, most of residuals fall within the $\pm 2 \mathrm{SD}$ indicating relatively a better fit, if at all not the perfect fit, of the model.

Dependent Variable: SR_?

Table 1-a

Method: Pooled Least Squares

Date: 06/06/08 Time: 23:22

Sample(adjusted): 2004:11 2008:02

Included observations: 40 after adjusting endpoints

Number of cross-sections used: 21

Total panel (balanced) observations: 840

White Heteroskedasticity-Consistent Standard Errors \& Covariance

\begin{tabular}{crrrr}
\hline \hline Variable & Coefficient & Std. Error & t-Statistic & Prob. \\
\hline \hline C & 0.001199 & 0.001699 & 0.705687 & 0.4806
\end{tabular}




\begin{tabular}{llllr}
\multicolumn{1}{c}{ FR_? } & 0.935699 & 0.018637 & 50.20654 & 0.0000 \\
\hline \hline R-squared & 0.863170 & Mean dependent var & 0.014072 \\
Adjusted R-squared & 0.863007 & S.D. dependent var & 0.121732 \\
S.E. of regression & 0.045056 & Sum squared resid & 1.701185 \\
Log likelihood & 1412.964 & F-statistic & 5286.380 \\
Durbin-Watson stat & 3.000055 & Prob(F-statistic) & 0.000000 \\
\hline \hline
\end{tabular}
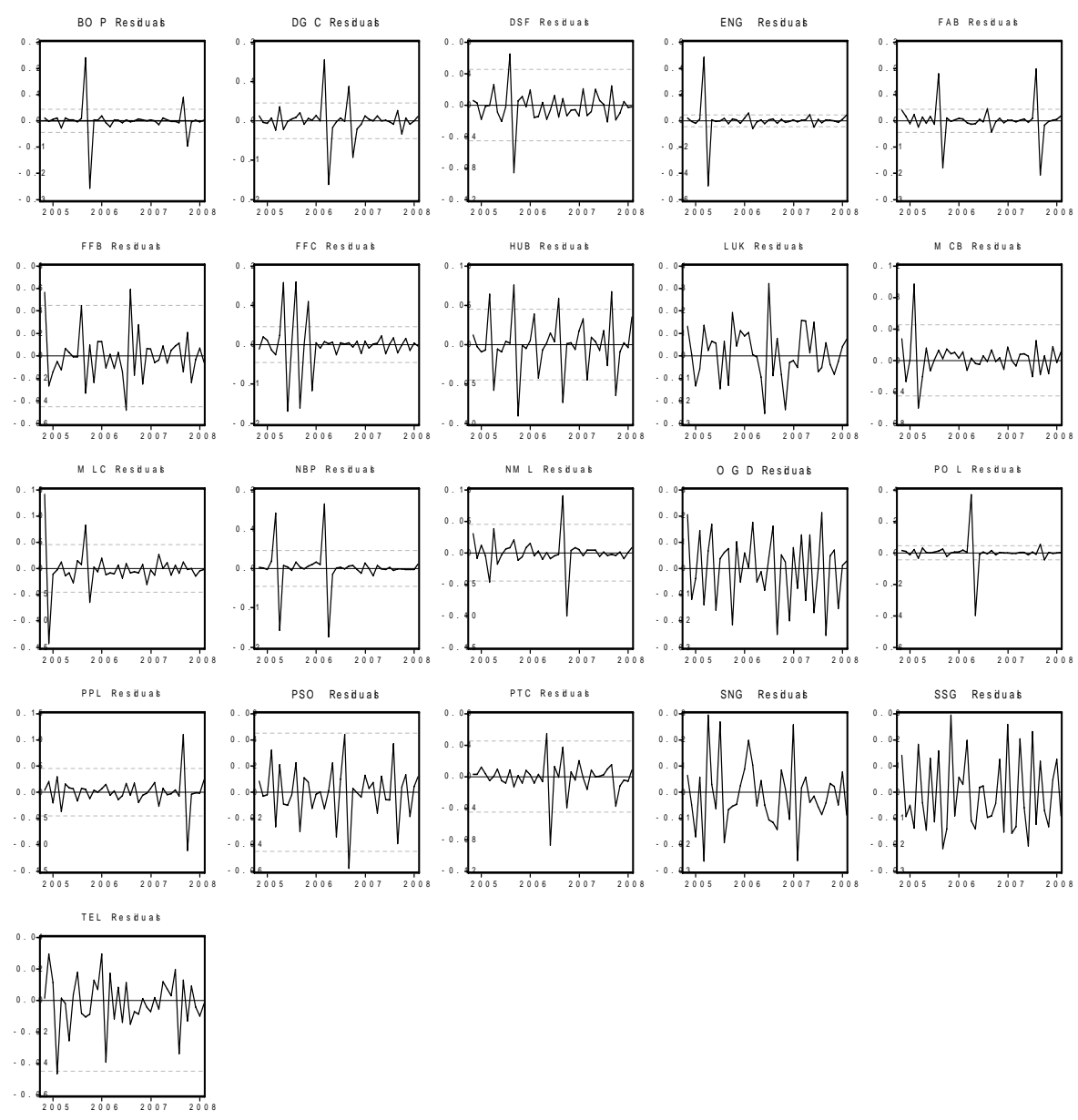
Dependent Variable: FR_?

Table 1-b

Method: Pooled Least Squares

Date: 06/06/08 Time: 23:19

Sample(adjusted): 2004:11 2008:02

Included observations: 40 after adjusting endpoints

Number of cross-sections used: 21

Total panel (balanced) observations: 840

White Heteroskedasticity-Consistent Standard Errors \& Covariance

\begin{tabular}{lrllr}
\hline \hline \multicolumn{1}{c}{ Variable } & Coefficient & Std. Error & t-Statistic & Prob. \\
\hline \multicolumn{1}{c}{ C } & 0.000777 & 0.001717 & 0.452357 & 0.6511 \\
\multicolumn{1}{c}{ SR_? } & 0.922487 & 0.033860 & 27.24396 & 0.0000 \\
\hline \hline R-squared & 0.863170 & Mean dependent var & 0.013758 \\
Adjusted R-squared & 0.863007 & S.D. dependent var & 0.120869 \\
S.E. of regression & 0.044737 & Sum squared resid & 1.677165 \\
Log likelihood & 1418.936 & F-statistic & 5286.380 \\
Durbin-Watson stat & 2.987037 & Prob(F-statistic) & 0.000000 \\
\hline \hline
\end{tabular}

\subsection{FIXED EFFECTS}

On account of limitations of the common constants, as specified in the section of methodology, the other panel tests such as fixed effects and random effects were considered.

Fixed effects incorporate the concept of different constants for each group. For the validity of the fixed effects, F-statistic with the assumption of homogeneity of constants against the heterogeneity was calculated. The value of F-statistic, being approximately 12 at 5 percent level of significance, rejects the null hypothesis in support of fixed effects against the common constants. AR term was included owing to the nature of the data being time series. There is negative autocorrelation but its intensity is extremely low (-0.482077). The Heteroscedasticity consistent covariance computes the Bollerslev-Wooldridge quasi-maximum likelihood (QML) standard errors. This QML is robust to the non-normality ${ }^{\text {xiii }}$ which exists in this data of 21 companies.

Graphs of the residuals are much better than the previously estimated values from common constants for all the 21 stocks. For almost all the stocks, most of residuals fall within the $\pm 2 \mathrm{SD}$ indicating relatively a better fit of the model.

166 
Dependent Variable: FR_?

Table 3-a

Method: Pooled Least Squares

Date: 06/06/08 Time: 23:43

Sample(adjusted): 2004:11 2008:02

Included observations: 40 after adjusting endpoints

Number of cross-sections used: 21

Total panel (balanced) observations: 819

Convergence achieved after 4 iteration(s)

White Heteroskedasticity-Consistent Standard Errors \& Covariance

\begin{tabular}{|c|c|c|c|c|}
\hline Variable & Coefficient & Std. Error & t-Statistic & Prob. \\
\hline SR_? & 0.952126 & 0.021060 & 45.20947 & 0.0000 \\
\hline $\operatorname{AR}(1)$ & -0.482077 & 0.112536 & -4.283761 & 0.0000 \\
\hline \multicolumn{5}{|l|}{ Fixed Effects } \\
\hline BOP--C & 0.000627 & & & \\
\hline DGC--C & 0.000739 & & & \\
\hline DSF--C & -0.000795 & & & \\
\hline ENG--C & 0.000636 & & & \\
\hline FAB--C & -0.000312 & & & \\
\hline FFB--C & 0.001515 & & & \\
\hline FFC--C & -0.000313 & & & \\
\hline HUB--C & -0.000480 & & & \\
\hline LUK--C & 0.001358 & & & \\
\hline MCB--C & 0.002830 & & & \\
\hline MLC--C & 0.001735 & & & \\
\hline NBP--C & 0.001580 & & & \\
\hline NML--C & 0.001374 & & & \\
\hline OGD--C & 0.001070 & & & \\
\hline POL--C & 0.000614 & & & \\
\hline PPL--C & 0.000560 & & & \\
\hline PSO--C & 0.000696 & & & \\
\hline PTC--C & 3.67E-05 & & & \\
\hline SNG--C & 0.000257 & & & \\
\hline SSG--C & 6.33E-05 & & & \\
\hline TEL--C & -0.000354 & & & \\
\hline R-squared & 0.895674 & Mean depen & tt var & 0.012676 \\
\hline Adjusted R-squared & 0.892791 & S.D. depend & var & 0.121979 \\
\hline S.E. of regression & 0.039939 & Sum squared & sid & 1.269740 \\
\hline Log likelihood & 1487.056 & F-statistic & & 6833.930 \\
\hline Durbin-Watson stat & 2.382203 & Prob(F-statis & & 0.000000 \\
\hline
\end{tabular}


For the regression of SR on FR, the fixed effects seem to have produced more significant results than the regression of FR on SR. The value of adjusted R-squared $(0.893418>0.892791)$, for the former regression, is relatively better. However, the coefficients of the stocks such as DSF-C, MLC - C, TEL-C posses surprisingly a negative sign. Whereas in the regression of FR on the SR the companies such as $\mathrm{DSF}-\mathrm{C}, \mathrm{FAB}-\mathrm{C}, \mathrm{FFC}-\mathrm{C}, \mathrm{HUB}-\mathrm{C}$ come up with negative sign.

It is not difficult to determine the direction of causal relationship. Future and spot prices move in the same direction. When future prices are high, returns from future stocks are high and this attitude positively affects the spot market returns.
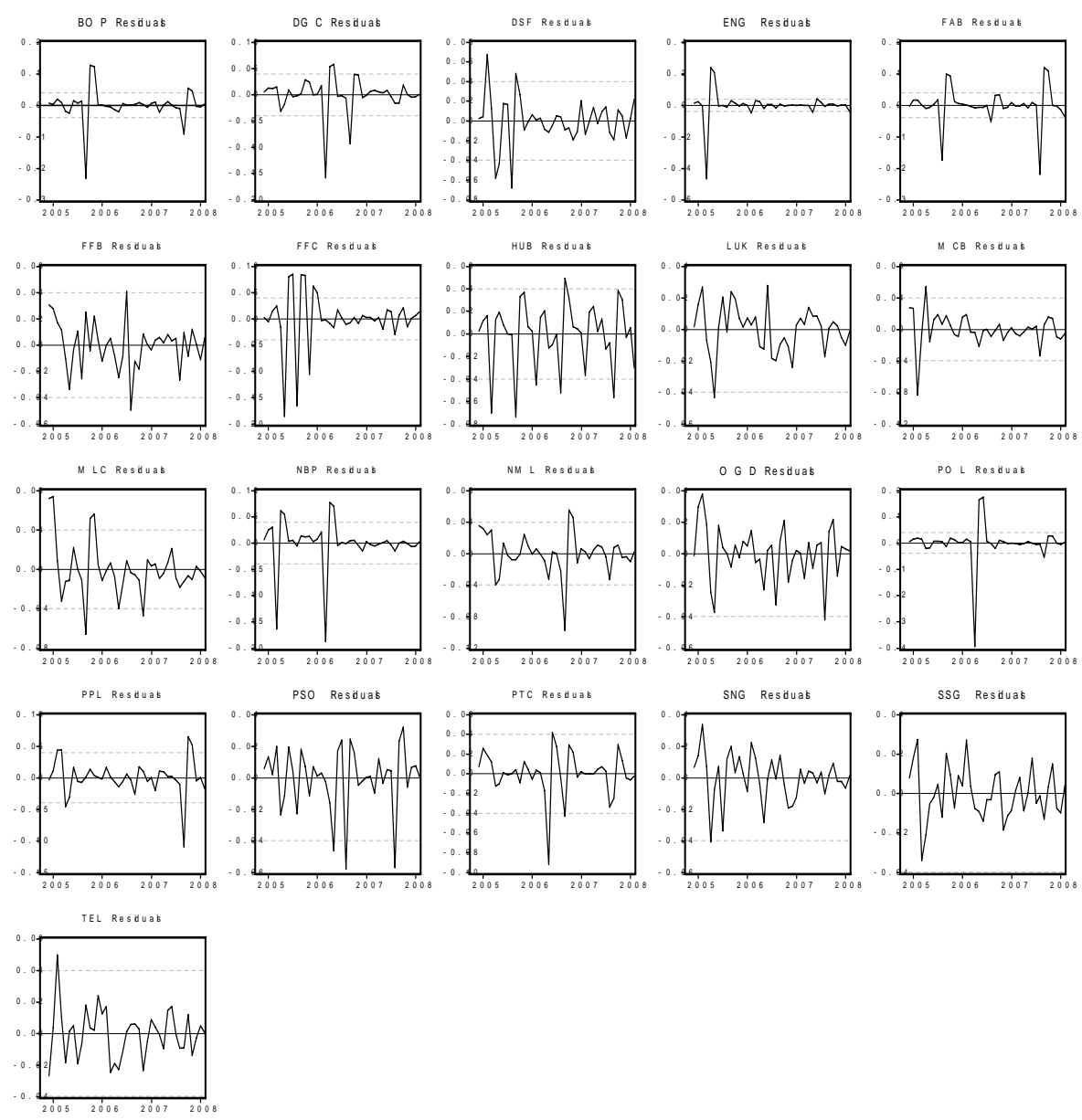

168 
Dependent Variable: SR_?

Table 3-b

Method: Pooled Least Squares

Date: 06/06/08 Time: 23:55

Sample(adjusted): 2004:11 2008:02

Included observations: 40 after adjusting endpoints

Number of cross-sections used: 21

Total panel (balanced) observations: 819

Convergence achieved after 5 iteration(s)

White Heteroskedasticity-Consistent Standard Errors \& Covariance

\begin{tabular}{crlrr}
\hline \hline Variable & Coefficient & Std. Error & t-Statistic & Prob. \\
\hline \hline FR_? & 0.958295 & 0.014937 & 64.15661 & 0.0000 \\
AR(1) & -0.484462 & 0.128594 & -3.767387 & 0.0002 \\
Fixed Effects & & & & \\
BOP-C & 0.000505 & & \\
DGC-C & 0.000884 & & \\
DSF-C & -0.000810 & & \\
ENG-C & 0.001789 & & \\
FAB-C & 0.001663 & & \\
FFB-C & $2.59 E-05$ & & \\
FFC-C & 0.000545 & & \\
HUB-C & 0.000609 & & \\
LUK-C & 0.001434 & & \\
MCB-C & 0.002042 & & \\
MLC-C & -0.003031 & & \\
NBP-C & 0.001299 & & \\
NML-C & 0.000348 & & \\
OGD-C & 0.000407 & & \\
POL-C & 0.000536 & & \\
PPL-C & 0.001203 & & \\
PSO-C & 0.000652 & & \\
PTC-C & $3.93 E-05$ & & \\
SNG-C & 0.000128 & & \\
SSG-C & 0.000247 & & \\
TEL-C & -0.000233 & & \\
Adjusted R-squared & 0.8934182529 & \\
S.E. of regression & 0.040067 & Sum squared resid & \\
Log likelihood & 1484.446 & F-statistic & \\
Durbin-Watson stat & 2.390038 & Prob(F-statistic) & \\
\hline \hline & & & \\
\hline \hline
\end{tabular}


https://ir.iba.edu.pk/businessreview/vol4/iss1/9

DOI: https://doi.org/10.54784/1990-6587.1171

Business Review - Volume 4 Number 1

January - June 2009

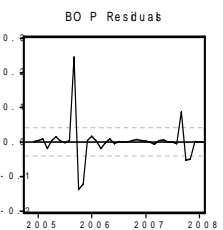

DG C Resiunał

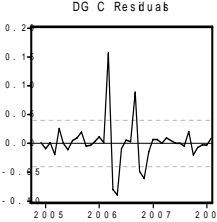

DSF Resduat
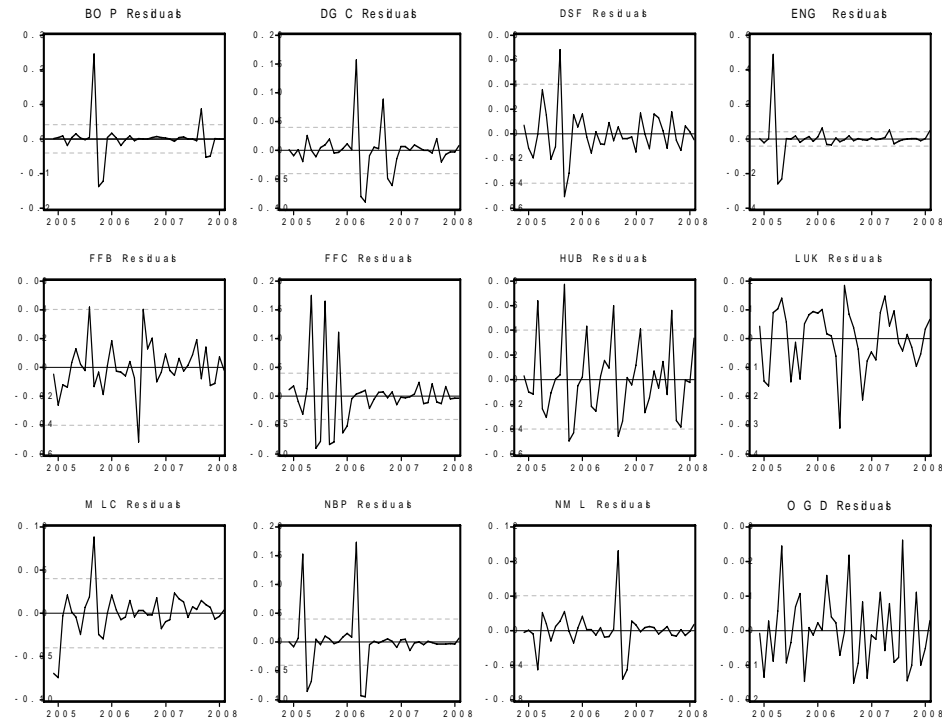

PPL Resitua

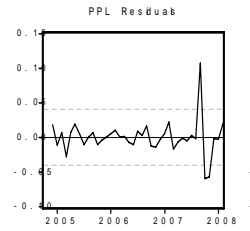

TEL Residuat

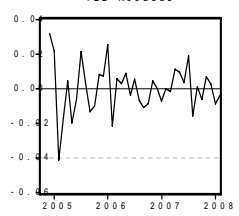

NBP Resituas

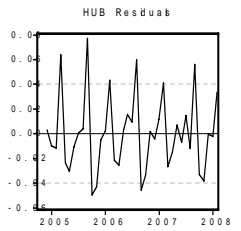

NM L Resiuas

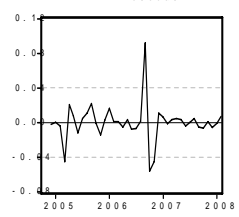

PTC Restuak
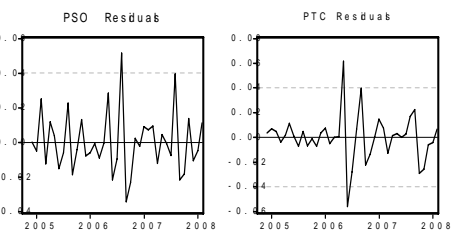
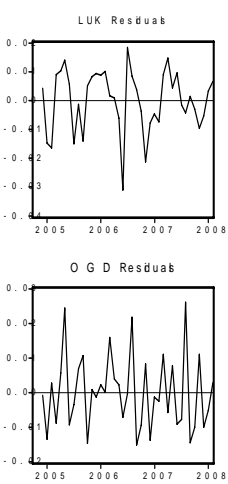

SNG Resiual

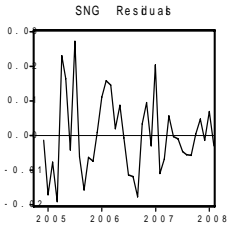

Fab Resuluas

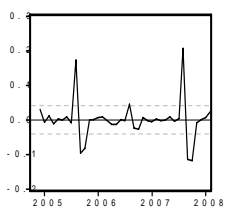

CB Restuat
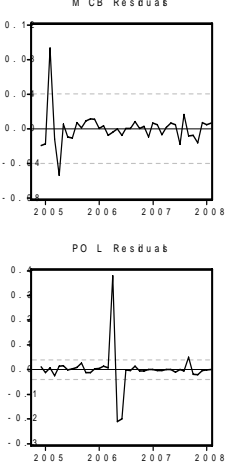

SSG Residuas

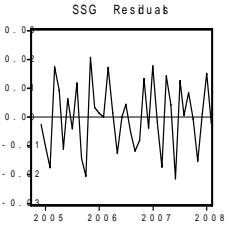

170 


\subsection{RANDOM EFFECTS}

Notwithstanding, the problems faced by the fixed effects model, as explained in the section of methodology, random effects model was employed and results have been reported in the Table 4-a and Table 4-b.

Table 4-a

Dependent Variable: SR_?

Method: GLS (Variance Components)

Date: 06/07/08 Time: 00:03

Sample: 2004:11 2008:02

Included observations: 40

Number of cross-sections used: 21

Total panel (balanced) observations: 840

\begin{tabular}{crrrr}
\hline \hline Variable & Coefficient & Std. Error & t-Statistic & Prob. \\
\hline \hline C & 0.000459 & 0.000142 & 3.224167 & 0.0013 \\
FR_? & 0.989433 & 0.006285 & 157.4343 & 0.0000 \\
Random Effects & & & & \\
BOP--C & 0.050544 & & & \\
DGC--C & -0.010723 & & & \\
DSF--C & 0.151833 & & & \\
ENG--C & -0.227277 & & \\
FAB--C & -0.314636 & & \\
FFB--C & 0.032313 & & \\
FFC--C & 0.055917 & & \\
HUB--C & -0.117778 & & \\
LUK--C & -0.026202 & & \\
MCB--C & -0.075753 & & \\
MLC--C & 0.105414 & & \\
NBP--C & 0.020770 & & \\
NML--C & 0.038017 & & \\
OGD--C & 0.039375 & & \\
POL--C & 0.032734 & & \\
PPL--C & -0.067262 & & \\
PSO--C & 0.019024 & & \\
PTC--C & 0.076608 & & \\
SNG--C & 0.082197 & & \\
SSG--C & 0.041125 & & \\
TEL--C & 0.093761 & & \\
\hline \hline
\end{tabular}




\begin{tabular}{lclr} 
S.E. of regression & 0.046169 & Sum squared resid & 1.786262 \\
Durbin-Watson stat & 2.945036 & & \\
\hline \hline \multicolumn{4}{c}{ Unweighted Statistics including Random Effects } \\
\hline \hline R-squared & 0.065878 & Mean dependent var & 0.014072 \\
Adjusted R-squared & 0.064764 & S.D. dependent var & 0.121732 \\
S.E. of regression & 0.117724 & Sum squared resid & 11.61377 \\
Durbin-Watson stat & 0.452963 & & \\
\hline \hline
\end{tabular}

Again, the results of the regression of SR on FR are relatively better than the regression of FR on SR. Both the GLS transformed regressions and unweighted statistics in terms of random effects are relatively better for the causal effect of future on the spot.

\section{Table 4-b}

Dependent Variable: FR_?

Method: GLS (Variance Components)

Date: 06/07/08 Time: 00:14

Sample: 2004:11 2008:02

Included observations: 40

Number of cross-sections used: 21

Total panel (balanced) observations: 840

\begin{tabular}{crrrr}
\hline \hline Variable & Coefficient & Std. Error & t-Statistic & Prob. \\
\hline C & $1.30 E-06$ & 0.000143 & 0.009129 & 0.9927 \\
SR_? & 0.977590 & 0.006217 & 157.2566 & 0.0000 \\
Random Effects & & & & \\
BOP--C & -0.055252 & & & \\
DGC--C & -0.028988 & & & \\
DSF--C & 0.031477 & & \\
ENG--C & 0.129141 & & \\
FAB--C & 0.305810 & & \\
FFB--C & -0.069071 & & & \\
FFC--C & 0.007029 & & \\
HUB--C & 0.192787 & & \\
LUK--C & -0.101734 & & \\
MCB--C & -0.187725 & & \\
MLC--C & 0.078036 & & \\
NBP--C & -0.144143 & & \\
NML--C & -0.081500 & & \\
OGD--C & -0.057709 & & \\
POL--C & -0.037743 & & \\
PPL--C & 0.024507 & & & \\
& & & & \\
\end{tabular}

172 


\begin{tabular}{lrll}
\multicolumn{1}{c}{ PSO--C } & -0.034372 & & \\
PTC--C & -0.001784 & & \\
SNG--C & -0.021455 & & \\
SSG--C & 0.017479 & & 0.013758 \\
TEL--C & 0.035211 & & 0.120869 \\
\hline \hline \multicolumn{5}{c}{ GLS Transformed Regression } \\
\hline \hline R-squared & 0.856020 & Mean dependent var & 1.764802 \\
Adjusted R-squared & 0.855848 & S.D. dependent var & \\
S.E. of regression & 0.045891 & Sum squared resid & \\
Durbin-Watson stat & 2.941192 & & 0.013758 \\
\hline \hline & Unweighted Statistics including Random Effects & \\
\hline \hline R-squared & 0.053360 & Mean dependent var & 11.60323 \\
Adjusted R-squared & 0.052230 & S.D. dependent var & \\
S.E. of regression & 0.117670 & Sum squared resid & \\
Durbin-Watson stat & 0.447343 & & \\
\hline \hline
\end{tabular}

The Hausman Test was applied in order to make a choice between the fixed effects and random effects. Further details about this test are given in the section on methodology. As specified earlier in the methodology that the Hausman statistic measures the distance between the fixed effects and the random effects estimators ${ }^{\mathrm{xiv}}$, the Hausman statistic was calculated. The value of this statistic calculated in the excel sheet comes out to be 1348.692716 which is highly significant at 1 per cent level of significance. Thus we are compelled to reject the $\mathrm{H}_{\mathrm{o}}$ hypothesis that random effects are consistent and efficient, against the $\mathrm{H}_{1}$, that random effects are inconsistent for this particular data set. Thus the fixed effects will be always consistent for this type of volatile data.

Hence, returns arising from the future prices lead the returns from the spot prices.

\section{CONCLUSIONS AND RECOMMENDATIONS}

This study looks into the lead-lag relation between index futures and the spot for the 21 companies included in the KSE-30 index. This study has been conducted consequent upon dissatisfactory results obtained from the time series econometric tests such as VAR, EG and ADF. However, the results from Panel data models, as an alternative methodology, more clearly determine future leading the spot. Hence, panel data models seem to be the most extensive way of testing statistical samples as they supplement all previous studies and successfully answer causality issues. Generally, the advantages of using panel data can be described as follows: 
(a) They provide more efficient estimations of parameters by considering broader sources of variation,

(b) They outsource more information to the analyst, and

(c) They allow the study of dynamic behaviour of the parameters.

The direction of relationship between the future and the spot prices leads the investors in the stock markets to take position for short-selling. Short-selling is one the market activities of the investors. The short-selling restrictions can enhance the informational efficiency of the stock market relative to the index futures. The leadlag relationship gets stronger when restrictions on short-selling are the least in the secondary markets. That was one of the temptations to investigate lead-lag relationship in this study. Moreover, the problems of over pricing and under pricing can also be rationalized. The study strongly recommends the role of arbitrage facility in the determination of lead-lag relationship in the presence of short-selling facilities. In order to determine better policy prescription, the quarters concerned are required to bring the data constraints at the minimum possible level enabling the researchers to employ better econometric methodologies. The financial institutions can be encouraged to facilitate arbitrage activities related to the secondary markets in the country.

\section{FOOT NOTES}

${ }^{1}$ Grunbichler, Longstaff, and Schwartz (1994) find lead from the DAX futures to spot is about 15 to 20 minutes. Niemeyer's (1994) shows one hour periods between the spot and futures leading to each other.

2 Fung and Jiang (1999).

${ }^{3}$ For more details please refer to the section of methodology.

${ }^{4}$ Cornell and French, (1983); Modest and Sundaresan, (1983)

${ }^{5}$ Kempf (1998).

${ }^{6}$ Kawaller, Koch, and Koch, (1987).

${ }^{7}$ Kleidon and Whaley (1992).

${ }^{8}$ Diamond and Verrecchia (1987).

${ }^{9}$ Cornell and Reinganum, (1981); French, (1983).

${ }^{10}$ Puttonon (1993).

${ }^{11}$ Methodology has been adapted from Asteriou (2006).

${ }^{12}$ Ahn and Moon (2001)

${ }^{13}$ Normality of the data was tested applying JB, Kurtosis, and skewness tests at different levels of significance. For space saving results have not been reported.

${ }^{14}$ Ahn and Moon (2001)

\section{REFERENCES}

Ahn S.C. and H.R. Moon, 2001. "Large-N and Large-T Properties of Panel Data 
Estimators and the Hausman Test, August 2001”, USC CLEO Research Paper No. C0120.

Asteriou, D. 2006. “Applied Econometrics: A Modern Approach”, Palgrave Macmillan, New York, N.Y. 10010.

Chan, K., 1992. “A Further Analysis of the Lead Lag Relation between the Cash Market And Stock Index Futures Market”, Review of Financial Studies 5, 123-152.

Cornell, B. and K. French, 1983. “Taxes and the Prices of Stock Index Futures”, Journal of Finance 38, 675-694.

Dickey, D.A. and Fuller, W.A. (1979): "Distribution of the Estimators for Autoregressive Time Series with a Unit Root", Journal of American Statistical Association, 74, 427-31.

Engle, R.F. and Granger, C.W.J. (1987): "Cointegration and Error Correction: Representation Estimation and Testing", Econometrica, 55, 251-276.

Fung, J.K.W. and L. Jiang, 1999. "Restrictions On Short-Selling And Spot-Futures Dynamics”, Journal of Business Finance and Accounting 26, 227-248.

Grunbichler, A., F.A. Longstaff, and E.S. Schwartz, 1994. "Electronic Screen Trading And The Transmission Of Information: An Empirical Examination”, Journal of Financial Intermediation 3, 166-187.

Hausman, J., 1978. “Specification Tests in Econometrics”, Econometrica, 46, pp.125171.

Kempf, A,, 1998. “Short Selling, Unwinding, And Mispricing”, Journal of Futures Markets 18, 903-923. Kleidon, A.W., and R.E. Whaley, 1992. One market? Stocks, futures, and options during October 1987, The Journal of Finance, 47, 851-877.

Modest, D.M. and Sundaresan, M., 1983. “The Relation Between Spot And Futures Markets”, Journal of Futures Markets 3, 15-42.

Niemeyer, J., 1994. “An Analysis of the Lead-Lag Relation between the OMX Index Forwards and the OMX Cash Index”, Paper presented to the Seventh Annual European Futures Symposium, Bonn. 
https://ir.iba.edu.pk/businessreview/vol4/iss1/9

DOI: https://doi.org/10.54784/1990-6587.1171

Business Review - Volume 4 Number 1

January - June 2009

The great bulk of those who do real harm are not criminals at all. A large group of them are tort-feasors...Another large group are merely fools politicians who negligently bankrupt nations and stupidly provoke wars, rhetoricians who teach in schools of business administration, and philosophers of law who confuse judges. - Philosophy in Context

Vol. 2, 1973, p. 39 